\title{
Complex and Controversial Roles of Eicosanoids in Fungal Pathogenesis
}

\author{
Susana Ruiz Mendoza ${ }^{1}$, Daniel Zamith-Miranda ${ }^{2}$, Tamás Takács $^{3}$, Attila Gacser ${ }^{3,4}$, \\ Joshua D. Nosanchuk ${ }^{2, *(\mathbb{D})}$ and Allan J. Guimarães ${ }^{1, *(\mathbb{D})}$ \\ 1 Laboratório de Bioquímica e Imunologia das Micoses, Departamento de Microbiologia e Parasitologia, \\ Instituto Biomédico, Universidade Federal Fluminense, Niterói 24210-130, RJ, Brazil; susa15_6@hotmail.com \\ 2 Departments of Medicine (Division of Infectious Diseases) and Microbiology and Immunology, \\ Albert Einstein College of Medicine, Bronx, NY 10461, USA; danielzamith@gmail.com \\ 3 Department of Microbiology, University of Szeged, 6726 Szeged, Hungary; \\ Takt@in1st.szote.u-szeged.hu (T.T.); gacsera@gmail.com (A.G.) \\ 4 MTA-SZTE Lendület Mycobiome Research Group, University of Szeged, 6726 Szeged, Hungary \\ * Correspondence: josh.nosanchuk@einsteinmed.org (J.D.N.); allanguimaraes@id.uff.br (A.J.G.); \\ Tel.: +1-718-430-2993 (J.D.N.); +55-21-2629-2410 (A.J.G.)
}

Citation: Mendoza, S.R.; Zamith-Miranda, D.; Takács, T.; Gacser, A.; Nosanchuk, J.D.; Guimarães, A.J. Complex and Controversial Roles of Eicosanoids in Fungal Pathogenesis. J. Fungi 2021, 7, 254. https://doi.org/10.3390/ jof7040254

Academic Editor: Joseph M. Bliss

Received: 2 March 2021

Accepted: 22 March 2021

Published: 28 March 2021

Publisher's Note: MDPI stays neutral with regard to jurisdictional claims in published maps and institutional affiliations.

Copyright: (c) 2021 by the authors. Licensee MDPI, Basel, Switzerland. This article is an open access article distributed under the terms and conditions of the Creative Commons Attribution (CC BY) license (https:// creativecommons.org/licenses/by/ $4.0 /)$.

\begin{abstract}
The prevalence of fungal infections has increased in immunocompromised patients, leading to millions of deaths annually. Arachidonic acid (AA) metabolites, such as eicosanoids, play important roles in regulating innate and adaptative immune function, particularly since they can function as virulence factors enhancing fungal colonization and are produced by mammalian and lower eukaryotes, such as yeasts and other fungi (Candida albicans, Histoplasma capsulatum and Cryptococcus neoformans). C. albicans produces prostaglandins (PG), Leukotrienes (LT) and Resolvins (Rvs), whereas the first two have been well documented in Cryptococcus sp. and H. capsulatum. In this review, we cover the eicosanoids produced by the host and fungi during fungal infections. These fungal-derived PGs have immunomodulatory functions analogous to their mammalian counterparts. Prostaglandin $\mathrm{E}_{2}\left(\mathrm{PGE}_{2}\right)$ protects $C$. albicans and C. parapsilosis cells from the phagocytic and killing activity of macrophages. H. capsulatum PGs augment the fungal burden and host mortality rates in histoplasmosis. However, $\mathrm{PGD}_{2}$ potentiates the effects and production of $\mathrm{LTB}_{4}$, which is a very potent neutrophil chemoattractant that enhances host responses. Altogether, these data suggest that eicosanoids, mainly $\mathrm{PGE}_{2}$, may serve as a new potential target to combat diverse fungal infections.
\end{abstract}

Keywords: eicosanoids; immune response; fungi; fungal eicosanoids; pathogenesis

\section{Introduction}

Fungal infections are a major global threat, particularly due to their increasing prevalence in immunocompromised patients [1], the limited number of therapeutic options, their chronicity, and frequently time-consuming diagnosis [2,3]. Classical virulence factors of pathogenic fungi include the presence of urease, proteases, heat shock proteins, melanins and a polysaccharidic capsule and other structures such as $\alpha$-glucans and mannans, among many others, which contribute to the spread of the pathogens and modulation of host immune responses [4]. During fungal infections the role of inflammatory mediators such as cytokines, growth factors and chemokines has been widely studied, and these products have been considered the main soluble protein mediators of host defense against pathogens. However, the role of lipid mediators during fungal infections has not been fully explored and a variety of unique lipids can also play important roles in regulating innate and adaptive immune functions [5-7].

Biologically active lipid mediators derive from omega-3 (n-3) and omega- 6 (n-6) polyunsaturated fatty acids (PUFA) [8] and include the 20-carbon arachidonic acid (AA; $(20: 4, n-6))$ and eicosapentaenoic acid (EPA; $(20: 5, n-3))$-derived eicosanoids and docosahexaenoic acid (DHA; 22:6(n-3))-derived docosanoids. These PUFAs, usually obtained from 
dietary sources or released from membrane phospholipids upon the hydrolysis of esterified fatty acids (FAs) by phospholipase A2 (PLA2), can be oxidized by three distinct main pathways involving cyclooxygenase (COX), lipoxygenase (LOX), and heme-containing cytochrome P450 (CYTP450) oxidase or epoxygenase enzymes (Figure 1) [8]. Classic n-6 PUFA AA-derived eicosanoids participate actively during immune responses $[4,9]$, and can be classified into the prostanoids such as prostaglandins (PGs), prostacyclin $\left(\mathrm{PGI}_{2}\right)$ and thromboxanes (TXs), in addition to leukotrienes (LTs) and lipoxins [10]. In contrast with lipoxins, which are formed from AA, the pro-resolving mediators (SPMs) such as protectins, resolvins (RVs) and maresins [11] have $n-3$ PUFAs as their precursors, i.e., EPA and DHA [12].

An important feature about AA-derived eicosanoids is their short response time, as their formation does not require protein synthesis, due to the fact that the AA precursor is present in mammalian cell membranes and the converting enzymes are usually constitutively expressed. However, these compounds can also be produced by lower eukaryotes, including yeasts and other fungi, having an active role during infection and representing a potential class of virulence factors $[4,13]$.

Prostaglandins (PGs) are five-carbon ring eicosanoids that are produced through the conversion of AA to prostaglandin $\mathrm{H}_{2}\left(\mathrm{PGH}_{2}\right)$ by the cyclooxygenase- 1 and -2 enzymes (prostaglandin endoperoxide $\mathrm{H}$ synthases COX-1 and COX-2, respectively) [5]. Depending on the following enzymatic step, $\mathrm{PGH}_{2}$ can be modified to produce different PGs $\left(\mathrm{PGF}_{2 \alpha}\right.$, $\mathrm{PGD}_{2}$, and $\left.\mathrm{PGE}_{2}\right)$, prostacyclin $\left(\mathrm{PGI}_{2}\right)$ or thromboxane $\mathrm{A}_{2}\left(\mathrm{TXA}_{2}\right)$ [14]. They regulate numerous processes throughout the body, such as kidney function, platelet aggregation, neurotransmitter release, and modulation of inflammatory responses, where they participate, among other tasks, in thermoregulation (inducing fever) and pain [5]. PGs bind to distinct types of GPCRs (G-protein coupled receptors), consisting of DP1 (Prostaglandin $\mathrm{D}_{2}$ receptor 1) and or CRTH2 (chemoattractant receptor-homologous molecule expressed on Th2 cells; also known as DP2, PG DP2 receptor) that recognize $\mathrm{PGD}_{2}$, rhodopsin-type receptors (EP1, EP2, EP3, EP4) that recognize $\mathrm{PGE}_{2}$, FP (prostaglandin F receptor) that recognizes $\mathrm{PGF}_{2 \alpha}$, IP (prostacyclin receptor) that recognizes $\mathrm{PGI}_{2}$, and TP (thromboxane receptor) that recognizes TXA 2 [15-18]. These GPCRs generate several second messengers and trigger distinct signal transduction pathways [19]. EP1 induces intracellular $\mathrm{Ca}^{2+}$ mobilization via the $\mathrm{G}_{\mathrm{q}}$ protein, whereas EP2 and EP4 increase cyclic adenosine monophosphate (cAMP) production via $G_{s}$ and EP3 inhibits adenyl cyclase (thus decreasing cAMP) via $G_{i}$ and elicits $\mathrm{Ca}^{2+}$ mobilization and phosphoinositide 3-kinase (PI3K) activation [15,20-23]. For these reasons, they modulate the activation of protein kinase A (PKA), transcription factors such as CREB [24], and extracellular signal-regulate kinases (ERKs) as well as the expression of cytokines during the immune response $[13,25,26]$. PGE $_{2}$ is the most studied PG, which is produced by several cells such as macrophages and fibroblasts, and has diverse effects on the regulation and activity of distinct cells [5]. For example, $\mathrm{PGE}_{2}$ can modulate the activity of professional antigen presenting cells (APCs) such as dendritic cells (DCs) and macrophages and the production of cytokines [5]. 


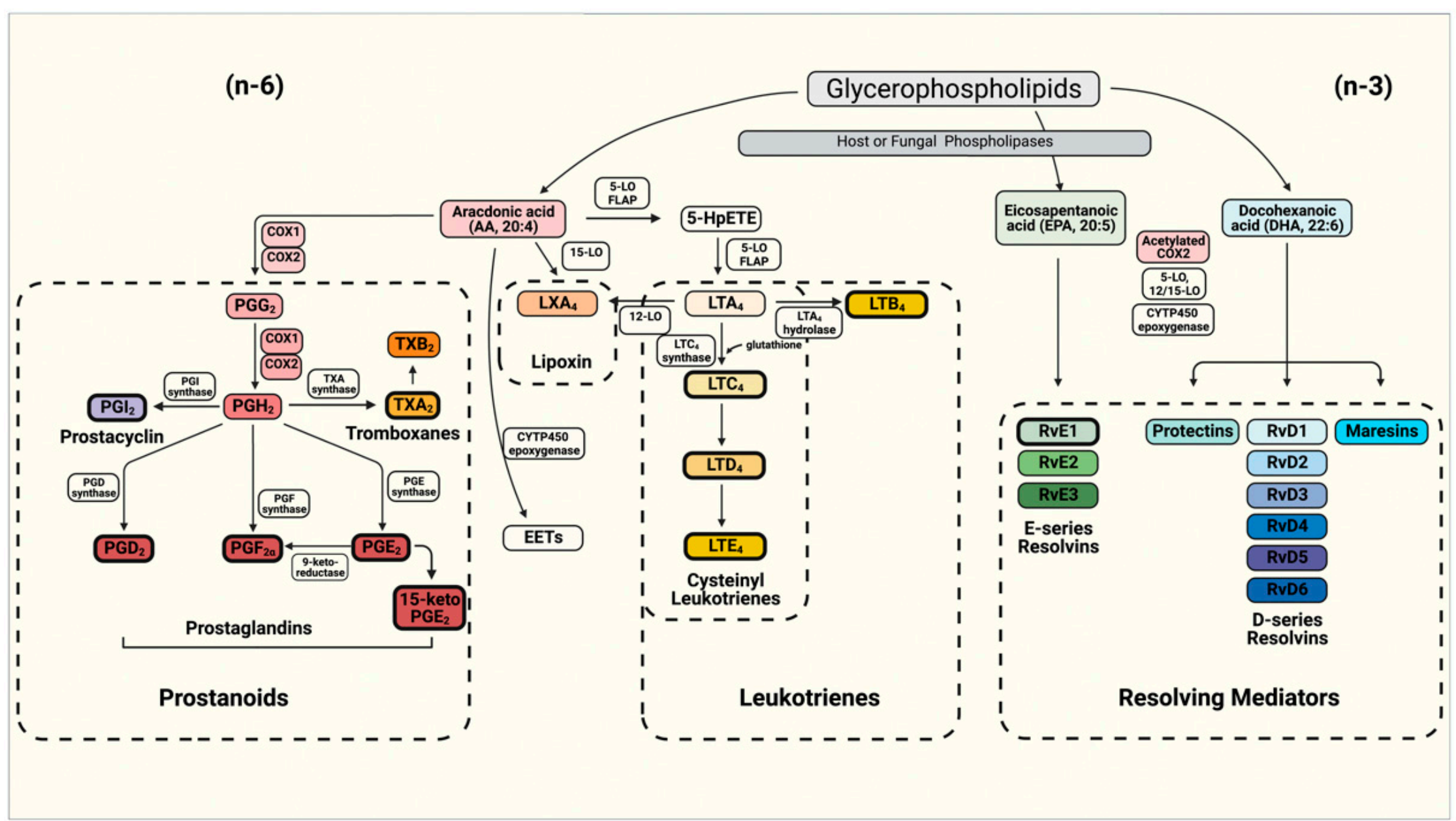

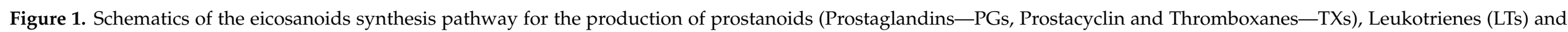
resolving mediators including D- and E-series resolvins (Rvs), protectins and maresins. The boxes depicted with bold borders illustrate the eicosanoids produced by fungi. 
Together with PGs in the prostanoid groups, thromboxanes (TXs) are produced as a six-member ether-containing ring upon the catalysis of the thromboxane synthase (TXS), producing the intermediate $\mathrm{TXA}_{2}$ or the final synthesis product $\mathrm{TXB}_{2}$ [10]. The thromboxane receptor (T prostanoid receptor, TP) is a GPCR, with either a $G_{q}$ or $G_{12 / 13}$ coupled subunit $[10,27]$. TXs are produced by several types of cells such as monocytes, macrophages, epithelial, and endothelial cells as well as platelets (thrombocytes), promoting the activation/aggregation and degranulation of platelets leading to the formation of blood clots $[10,28,29]$. TXA 2 is the most potent known vasoconstrictor, and its proinflammatory action occurs by enhancing the activation of monocytes, cytokine production, expression of leukocyte adhesion molecule, and vascular permeability [29]. TXA 2 also promotes T-cell activation and proliferation, and facilitates the development of effector cytolytic T-cells [7]. For instance, $\mathrm{TXA}_{2}$ participates in the damage caused by ischemic injury and inflammation in acute stages of Trypanosoma cruzi infections [29], exacerbates acute lung injury by promoting edema formation [27] and its excessive production causes significant hyper-permeability, resulting in severe edema by disrupting the endothelial barrier via $\mathrm{Ca}^{2+} /$ Rho kinase signaling [30]. In addition to these immunomodulatory functions, TXs receptors (TPs) are expressed in high levels in the thymus where they participate in the negative selection of maturing $\mathrm{T}$ lymphocytes $[7,30]$.

Leukotrienes (LTs) are synthetized from AA by the enzyme 5-lipoxygenase (5-LO) and 5-lipoxygenase activating protein (FLAP) into 5-hydroperoxyeicosatetraenoic acid (5- HpETE), which is further metabolized into leukotriene $\mathrm{A}_{4}\left(\mathrm{LTA}_{4}\right)$, the precursor of all forms of LTs [31]. LTA $_{4}$ is converted by $\mathrm{LTA}_{4}$ hydrolase (LTA4H) into leukotriene $\mathrm{B}_{4}\left(\mathrm{LTB}_{4}\right)$, or it can be conjugated with reduced glutathione by leukotriene $\mathrm{C}_{4}\left(\mathrm{LTC}_{4}\right)$ synthase to yield the cysteinyl leukotriene (CysLT) LTC $_{4}$ and its derivatives [31]. LTB $_{4}$ and $\mathrm{LTC}_{4}$ are exported via the specific ATP-binding cassette (ABC) transporters- 1 and -4 , whereas further released $\mathrm{LTC}_{4}$ is converted to leukotriene $\mathrm{D}_{4}\left(\mathrm{LTD}_{4}\right)$, which can undergo further conversion into leukotriene $\mathrm{E}_{4}\left(\mathrm{LTE}_{4}\right)[31,32]$. LT receptors are also GPCRs located on the outer plasma membrane of resident and inflammatory cells, among other cell types. They induce the increase in intracellular $\mathrm{Ca}^{2+}$ and the reduction in intracellular cAMP levels [31,33,34]. LTB 4 binds to BLT1 and BLT2 receptors, whereas the most known receptor of cysteinyl LTs is the type 1 CysLT receptor (CysLTR1), with high affinity for LTD4 and it is the target for antagonists clinically used for the management of asthma, such as Montelukast, Zafirlukast and Pranlukast [31,32,34,35]. LTs play an important role in amplifying the inflammatory responses to infection [31]. LTB $_{4}$ participates in the activation and recruitment of neutrophils, macrophages, monocytes, mast cells, and T lymphocytes, while increasing phagocytosis, microbicidal activity, and generating and modulating chemokines and cytokines [31]. It is one of the main modulators of the activation and maintenance of the innate and adaptive immune response $[35,36]$. Fungal zymosan and peptidoglycan from Aspergillus fumigatus induce the production of LTs in the airways that contributes to the initiation of asthma and causes and exacerbates potent bronchoconstrictive effects, such as edema through vasodilation, increased vascular permeability, and enhanced recruitment of effector cells [37]. In contrast, gliotoxin from $A$. fumigatus suppresses the biosynthesis of $\mathrm{LTB}_{4}$ by direct interference with LTA4H activity resulting in impaired neutrophil functions [38-40].

Non-classical eicosanoids compose the group of specialized pro-resolving mediators (SPM) also called resolvins (Rvs) [8]. SPMs derived from EPA are designated E-series Rvs (Resolvin E1 or RvE1, RvE2 and RvE3), whereas those from DHA are referred to as D-series RVs (RvD1-6) [12,41] (Figure 1). Four further metabolites of DHA have a hydroxyl group at the 13-position and have been designated as 13-series resolvins (RvT). DHA is converted to three Rvs of which RvD1(n-3DPA) is the most abundant [8]. RVs are involved in the resolution stage of inflammation, ending the chronicity of the inflammatory process and, hence, reducing or preventing tissue damage [11,12]. RvE1 is an eicosanoid that protects human tissues from leukocyte regulated inflammatory processes [42-44]. RvE1 dramatically reduces dermal inflammation, peritonitis and interleukin (IL) production 
and inflammatory pain [45]. RvE2 can effectively reduce joint pain in arthritis [11]. RvD2 ameliorates bacterial sepsis, with RvD3 acting in later stages of resolution and RvD4 helping the clearance of apoptotic cells by skin fibroblasts [8]. In general, RvDs also block tumor necrosis factor (TNF)- $\alpha$-induced IL-1 $\beta$ transcripts and are potent regulators of PMN infiltration in brain, skin, and peritonitis in vivo [11,12].

\section{Molecular Basis of Eicosanoid Production in Fungi}

The molecular background of eicosanoid biosynthesis was first revealed in mammals, with the description of three main enzymes pathways (COX, LO, and CYTP450) [46]. Eicosanoid production in yeasts was first uncovered in the early 1990's in the non-pathogenic fungus Dipodascopsis uninucleata. Van Dyk and colleagues isolated a 20-carbon chained AA metabolite identified as 3-hydroxy-5,8,11,14- eicosatetraenoic acid (3-HETE) [47]. Later, the same oxylipid was found in other yeasts of Dipodascaceae spp. and the filamentous Mucor spp. and Rhizomucor spp. [48,49]. Noverr et al. [13] examined several pathogenic fungi for the production of eicosanoids, and each analyzed species was able to produce compounds that eluted together with mammalian PGs and LTs, in the absence and presence of exogenous AA, by either, respectively de novo or a "trans-species" mechanism with fungal phospholipases acting on host phospholipids (Figure 2) [6].

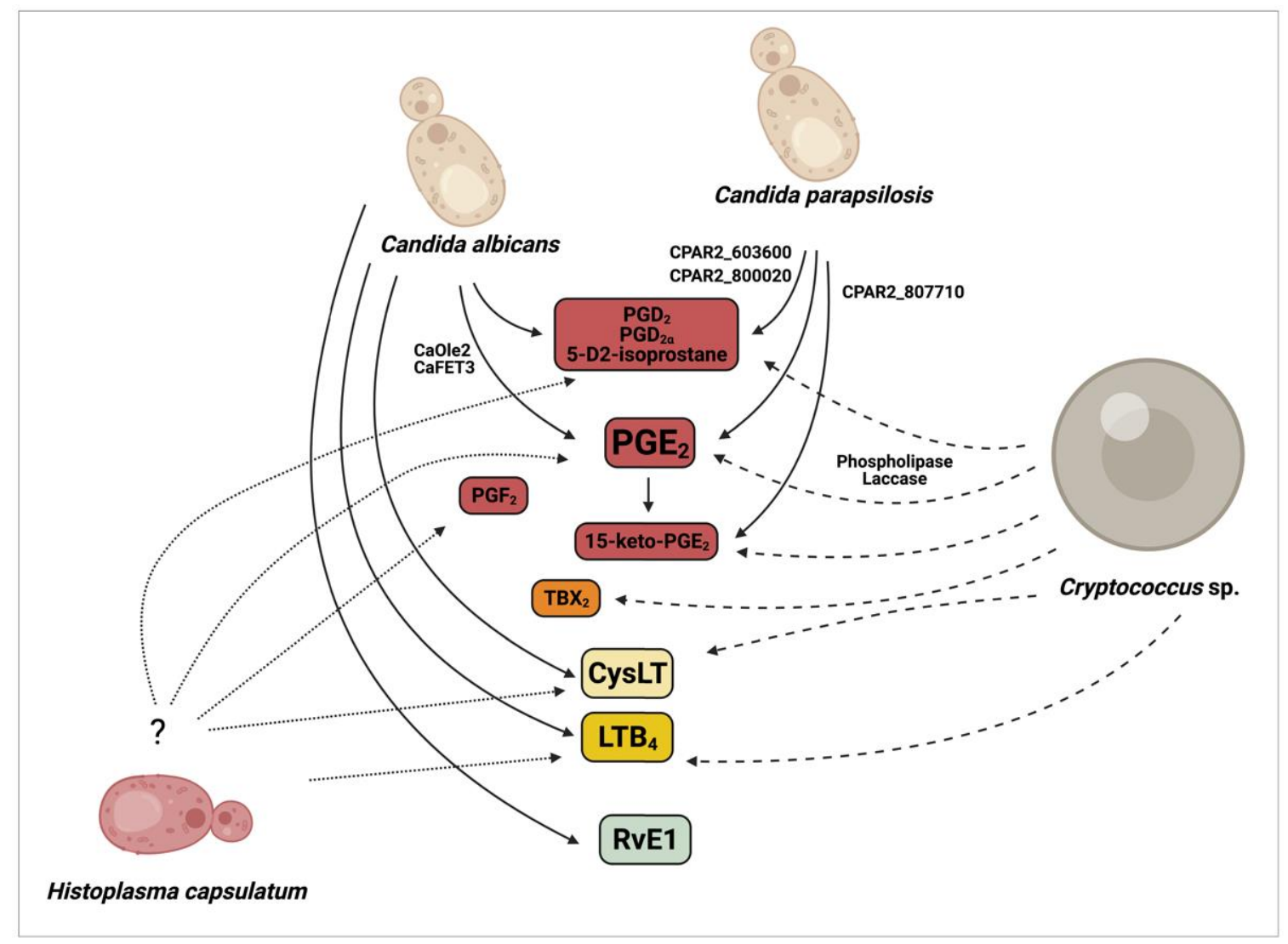

Figure 2. Eicosanoids production in Candida sp., Cryptococcus sp. and Histoplasma capsulatum. The figure illustrates genes involved in the synthesis of eicosanoids, with exception of H. capsulatum, with as yet undescribed genes involved. Lines and arrows indicate the eicosanoids produced by Candida sp. (solid lines), Cryptococcus sp. (dashed lines) and H. capsulatum (dotted lines).

However, whole genome sequencing analyses revealed that fungi have no homologues for the abovementioned mammalian enzymes, suggesting that fungi have evolved alternative routes for the synthesis of eicosanoids [46]. Yet, the use of COX inhibitors, such as aspirin, indomethacin, and etodolac and the inhibition of the LO pathway with 
nordihydroguaiaretic acid inhibited eicosanoids production and clearly impacted growth of Cryptococcus neoformans and Candida albicans, offering a link between fungal growth and eicosanoid production [50-52].

\subsection{Production of Eicosanoids by Candida albicans and Non-Albicans Species}

Deva et al. revealed that the opportunistic human fungal pathogen $C$. albicans produces 3,18-dihydroxy-5,8,11,14- eicosatetraenoic acid (3,18-di-HETE) by utilizing exogenous AA [53]. A subsequent study reported that, besides 3,18-di-HETE, C. albicans synthesizes an uncharacterized prostaglandin $\left(\mathrm{PGE}_{\mathrm{x}}\right)$ [50]. This eicosanoid was later shown to be indistinguishable from mammalian $\mathrm{PGE}_{2}$ [52]. Further investigations identified two non$\mathrm{COX} / \mathrm{LO} / \mathrm{CYTP} 450$-related enzymes, namely the fatty acid stearyl-coenzyme A desaturase (Ole2) and the multicopper ferroxidase (Fet3), which are potentially involved in C. albicans (Ca) $\mathrm{PGE}_{2}$ biosynthesis (Figure 2) [13,52]. Homozygous deletion of both the fatty acid desaturase CaOLE2 and the multicopper oxidase CaFET3 resulted in a significant reduction in $\mathrm{PGE}_{2}$ synthesis by approximately $50-70 \%$ and $40-50 \%$, respectively. However, $\mathrm{PGE}_{2}$ levels were still measurable in the corresponding homozygous mutant suggesting the presence of yet undiscovered PGs regulatory pathways in this species. C. albicans is also able to produce other PGs, such as $\mathrm{PGD}_{2}$ and $\mathrm{PGD}_{2 \alpha}[13,52]$.

Besides C. albicans, several non-albicans Candida species such as $C$. dubliniensis, $C$. tropicalis, C. glabrata, and C. parapsilosis synthesize $\mathrm{PGE}_{2}$ [54-56], all of which are frequently associated with human fungal infections. HPLC-MS analysis of the fatty acid biosynthesis of $C$. parapsilosis by Grózer and colleagues revealed that this species, similar to C. albicans, is able to produce various PGs besides $\mathrm{PGE}_{2}$, and highlighted $\mathrm{PGD}_{2}$ as another major eicosanoid produced by C. parapsilosis [56]. A 2018 follow-up study with C. parapsilosis also identified an uncommon oxylipin, an autoxidative isomer of $\mathrm{PGD}_{2}$ (5-D2-IsoProstane) secreted upon incubation with exogenous AA (Figure 2) [57].

However, our knowledge of its biosynthesis is scarce [58]. A recently published study by Chakraborty and colleagues aimed to identify the molecular basis of PG production in C. parapsilosis and identified several genes involved in the process [57]. These include CPAR2_603600 (a homologue of the CaFET3), CPAR2_807710 (Acyl-CoA oxidase in S. cerevisiae, ScPOX1-3) and CPAR2_800020 (Acyl-CoA thiolase in S. cerevisiae, ScPOT1) (Figure 2). $\mathrm{LC} / \mathrm{MS}$ data revealed that $C$. parapsilosis' $\mathrm{PGE}_{2}$ biosynthesis is decreased by approximately $60-70 \%$ if any of these genes are disrupted. The double deletion of CPAR2_603600 and CPAR2_800020 leads to about $80 \%$ decrease in PGD2 production, suggesting their significant role in its biosynthesis. Their removal also effected the secretion of $15-$ keto- $\mathrm{PGE}_{2}$, a metabolite generated by the degradation of PGE2. CPAR2_807710 was shown to be most involved in 15-keto- $\mathrm{PGE}_{2}$ production. In contrast to $C$. albicans, the homologue of CaOLE2 has no significant role in $\mathrm{PGE}_{2}$ biosynthesis in C. parapsilosis [56].

Notably, in addition to PGs, C. albicans also utilizes AA for the biosynthesis of LTs, such as $\mathrm{LTB}_{4}$ and CysLTs (Figure 2) [13]. During Candida spp. infection, the synthesis of some LTs is altered to reduce host immune responses as a strategy for the establishment and maintenance of the infection [35]. $\mathrm{LTB}_{4}$ and CysLT production are both mediated by lipoxygenases through the production of 5-HpETE from exogenous AA [13], whereas RvE1 synthesis in C. albicans is produced from EPA [42], and some biosynthetic precursors (18-HEPE, 15-HEPE and 5-HEPE), by neutrophil 5-lipoxygenase principally, cytochrome P450 monooxygenase enzymes (CYP45), and other specific enzymes remain unknown [13,42,59]. The detailed biosynthetic pathway of LTs and RvE1 in C. albicans also remains enigmatic. Other human pathogenic non-albicans Candida species such as C. dubliniensis, C. tropicalis, and C. glabrata may also be able to produce these eicosanoids; however, this remains unconfirmed.

\subsection{Production of Eicosanoids by Cryptococcus sp.}

C. neoformans produces biologically active eicosanoids from exogenous sources of AA during infection, which are indistinguishable from host eicosanoids and modulate host defenses [50,51]. The major AA metabolite produced is an authentic $\mathrm{PGD}_{2}$, but 
the fungus is also able to produce heptadecatrienoic acid, 5-HETE, $\mathrm{PGF}_{2}, \mathrm{TXB}_{2}$, and $\mathrm{PGE}_{2}$ [50]. Two enzymes expressed by C. neoformans, phospholipase B1 (PLB1) and laccase (CNLAC1 gene), are believed to be associated with cryptococcal eicosanoid synthesis (Figure 2). Pharmacological enzymatic inhibition or deletion of phospholipase B1 $(\Delta p l b 1)$ reduces secreted levels of all eicosanoids produced by $C$. neoformans $[60,61]$. In turn, deletion of laccase ( $\Delta$ lac1 mutants) or enzymatic inhibition by anti-lac1 antibody resulted specifically in the loss of $\mathrm{PGE}_{2}$ [51]. The addition of $\mathrm{PGE}_{2}$ was sufficient to promote growth of $\Delta p l b 1$ and $\Delta l a c 1$ in vitro and in vivo, independently of host $\mathrm{PGE}_{2}[60,61]$. In fact, laccase is an important virulence factor for $C$. neoformans with a broad spectrum oxidase activity, converting polyphenolic compounds into the cell wall pigment melanin, and this polymer protects $C$. neoformans against oxidants, microbiocidal proteins and antifungals as well as to phagocytosis and killing by macrophages $[62,63]$. Additionally, recombinant laccase readily converts $\mathrm{PGG}_{2}$ into $\mathrm{PGE}_{2}$ and $15-$ keto- $\mathrm{PGE}_{2}$, and it is suggested as a key cryptococcal prostaglandin enzyme for this recently described unique production pathway (Figure 2) [51].

\subsection{Production of Eicosanoids by Histoplasma Capsulatum}

Although Histoplasma capsulatum can produce eicosanoids [13,54], further studies are necessary to dissect the pathways involved in their production and to determine whether they play a role during infection (Figure 2).

\section{The Role of Eicosanoids during Fungal Infections}

The production of eicosanoids by pathogenic fungi, such as C. albicans, C. dubliniensis, C. glabrata, C. tropicalis, C. neoformans, H. capsulatum and A. fumigatus is linked to the pathogenesis of each fungal infection $[4,9,51,60,64-66]$. Some fungal-derived eicosanoids can enhance both fungal colonization and induce immunomodulatory effects. Overall, fungal LTs act by enhancing the acute inflammation, whereas PGs have negative effects on innate and cellular Th1 responses against mycosis, resulting in immunological tolerance and contributing to the chronicity of fungal infections [13]. Herein, we discuss the roles of eicosanoids in three major fungal infections.

\subsection{Eicosanoids in Candidiasis}

Eicosanoids play an important role in both sides of the host-Candida interaction. Depending on the organ or tissue environment, host-derived PGE $_{2}$ either decreases $[64,67]$ or improves $[68,69]$ the protective Th1 and Th17 responses that particularly may help the host restrain C. albicans at barrier surfaces and in the bloodstream.

C. albicans induces host cells to release AA from membrane phospholipids and infection-derived stimuli can also induce COX-2 expression and trigger the synthesis of PGs in various cells types $[66,70]$. C. albicans stimulates AA metabolism and the generation of $\mathrm{PGE}_{2}$ by synovial fibroblast, alveolar and peritoneal macrophages, and epithelial cells via stimulation of TLR2 and TLR4 [14]. Candida mannans and $\beta$-1,3-glucan induce $\mathrm{PGE}_{2}$ via stimulation of mannose receptor and dectin-1 in peripheral blood mononuclear cells, respectively [71]. $\mathrm{PGE}_{2}$ signaling stimulates Th2 and Th17 responses to yeast and limits the ability of macrophages to clear Candida sp. [71].

Although the exact role of Candida-derived eicosanoids during host-pathogen interactions is largely undiscovered, a limited number of studies are available that provide insights into how these lipid metabolites affect fungal virulence [57,67]. Many studies have pointed out the major role of host derived $\mathrm{AA}$ and fungi derived $\mathrm{PGE}_{2}$ in the modulation of yeast cell growth, morphogenesis, and biofilm formation in C. albicans [50,55]. In contrast, some studies focusing on the negative impact of $\mathrm{PGE}_{2}$ on yeast biology have shown that $\mathrm{PGE}_{2}$ inhibits germ tube formation by antagonizing yeast to hyphal transformation in $C$. albicans, which may limit tissue invasion [72].

In a previous study, the PGE $_{2}$ biosynthesis associated genes OLE2, FET3, and FET31 were knocked out in C. albicans strains and the mutant's capacity for $\mathrm{PGE}_{2}$ secretion was 
decreased in vitro. The authors examined the killing of the mutants by macrophages and immune-modulatory effects in vitro as well as their capacity for organ colonization ability in various mouse models of invasive candidiasis. The ole $2^{-/-}$showed similar fitness and rates of hyphal formation than the wild-type (WT) counterpart. However, the gut colonizing capacity of the ole $2^{-1-}$ strain decreased compared to the WT strain. Besides its role in promoting colonization and survival in the mouse gut, $C$. albicans derived $\mathrm{PGE}_{2}$ also inhibited fungal cell internalization by phagocytes [65]. However, in CD11b+ DC and macrophage depleted mice, the WT C. albicans strain was not able to overgrow the ole2 ${ }^{-/-}$strain [65], suggesting that the presence of $\mathrm{PGE}_{2}$ is beneficial for fungal growth, overcoming phagocytosis, and enhancing survival within the host.

Regarding non-albicans Candida species, the presence of AA increases biofilm formation and $\mathrm{PGE}_{2}$ production by $C$. glabrata, C. parapsilosis, and C. tropicalis [58]. These findings suggest that Candida spp. evolved the capacity to produce PGs, primarily $\mathrm{PGE}_{2}$, to enhance their fitness and survival within certain niches of the host that could directly promote the fungus' pathogenesis upon a potential commensal-to-pathogenic shift event. The work of Chakraborty and colleagues suggests that fungal-derived PGs in C. parapsilosis also negatively regulate yeast cell phagocytosis and killing by macrophages, as PGs $\left(\mathrm{PGE}_{2}, \mathrm{PGD}_{2}\right.$, and 15-keto-PGE 2 )-deficient $C$. parapsilosis cells were more susceptible to phagocytosis and killing by human peripheral blood monocyte-derived macrophages (PBMC-DM) compared to the WT strain [57]. As the virulence of PG deficient $C$. parapsilosis mutant strains also decreased in vivo compared to the WT strain, fungal PGs could also actively contribute to the virulence of this species.

These observations, together with other previous reports, suggest that fungi-derived prostaglandins have immunomodulatory functions analogous to their mammalian counterparts $[54,73]$. To further support this suggestion, another study reported that C. albicans-produced $\mathrm{PGE}_{2}$ up-regulates anti-inflammatory responses through enhancing IL-10 released by murine splenocytes. Moreover, the levels of mouse keratinocyte-derived chemokine (KC, analog to human IL-8) and other pro-inflammatory cytokines, such as $\mathrm{TNF} \alpha$, decreased after $24 \mathrm{~h}$ of fungal $\mathrm{PGE}_{2}$ treatment $[67,71]$. Fungal-derived $\mathrm{PGE}_{2}$ decreases the killing of $C$. albicans by intestinal macrophages, supporting the idea that fungal prostaglandins could also inhibit the killing activity of host cells.

A similar conclusion can be drawn for C. parapsilosis, where the absence of PGE2 -related genes increased the expression of pro-inflammatory cytokines such as pro-IL$1 \beta$, IL- 6 and TNF $\alpha$ [57]. Thus, C. parapsilosis $\mathrm{PGE}_{2}$ could also negatively regulate host inflammatory responses. In C. parapsilosis, PGs production actively contributes to host cell damage, as revealed by the decreased [57] death of PBMC-DMs following infection with PG-deficient strains compared to the WT strain. C. parapsilosis PGs secretion is also suggested to contribute to organ colonization when studied in a mouse model of systemic candidiasis. However, the studied PG-related genes contributed unequally to the fungal load of each examined organ, which may suggest that the observed effect is not solely due to the presence of fungal $\mathrm{PGE}_{2}, \mathrm{PGD}_{2}$ and 15-keto- $\mathrm{PGE}_{2}$ [57].

LTs were also described as biologically active immunomodulatory eicosanoids [74,75]. Host-derived LTs increase capillary permeability, and activate and recruit eosinophils and neutrophils [75]. The present literature lacks information about the immunomodulatory function of fungal-derived LTs. However, a recent study showed that the amount of LTF4 increased in patients with candidemia, suggesting that LTF4 may also contribute to host responses to Candida spp. [35].

A previous study in 2007 showed that $C$. albicans-derived RvE1 is chemically identical to the human RvE1 [42]. When administered at low concentrations, fungal RvE1 reduced the IL-8-mediated chemotaxis of human neutrophils and also the recruitment of DCs [42,59]. In contrast, higher doses of fungal RvE1 enhanced phagocytic activity and fungicidal reactive oxygen species (ROS) production by human neutrophils against $C$. albicans. Interestingly, inoculation of RvE1 into mice with fungemia due to C. albicans, led to a more rapid clearance of the pathogen from the bloodstream [42]. These facts suggest that 
low concentrations of fungal RvE1 protects C. albicans due to the inhibition of neutrophil recruitment, although higher fungal burden (together with increased fungal RvE1 levels) could act as an alarming signal for neutrophils, which would then be able to control and restrict fungal invasion.

\subsection{Eicosanoids in Cryptococcosis}

C. neoformans secretes phospholipase B (PLB), which is a virulence factor. This single cryptococcal protein has three separate enzymatic activities: phospholipase B (PLB), which removes both acyl chains simultaneously from phospholipids; lysophospholipase (LPL), which removes the single acyl chain from lysophospholipids; and lysophospholipase transacylase (LPTA), which adds an acyl chain to lysophospholipids to form phospholipids [61]. Despite the lack of understanding on the structure and mechanism of action of PLB, this enzyme is involved in the survival of Cryptococci within macrophages, the destruction of lung tissue and the production of eicosanoids, which modulate phagocytic activity [61]. As mentioned, C. neoformans produces eicosanoids from exogenous AA and utilizes them to modulate the immune response favoring its own survival. For instance, $\mathrm{LTB}_{4}$ significantly reduced neutrophil recruitment in the lung vasculature of mice infected intravenously with $C$. neoformans, demonstrating a critical role of $\mathrm{LTB}_{4}$ in intravascular neutrophil swarming during infection [76]. The presence of CysLTs and $\mathrm{LTB}_{4}$ produced by C. neoformans strains B-3501A and H99 through the activity cryptococcal phospholipase cPLA $2 \alpha$ and 5-LO, can contribute to fungal penetration of the blood-brain barrier in vitro and in vivo, specifically facilitating central nervous system (CNS) infection [77].

C. neoformans is also able to modulate the host inflammatory state during infection by directly manipulating host eicosanoids signaling and $\mathrm{PGE}_{2}$ is considered a mediator of cryptococcal virulence $[60,78]$. During macrophages infection, C. neoformans produces the dehydrogenated form of $\mathrm{PGE}_{2}$ (15-keto-PGE $)$ enhancing its virulence via the activation of the host nuclear transcription factor, PPAR- $\gamma$ [60]. In C. neoformans infections, the use of antagonists of either EP2 or EP4 receptors improves the host defense by promoting TLR-4mediated cytokine production, and enhancing M1 macrophage polarization followed by yeast killing [78].

\subsection{Eicosanoids in Histoplasmosis}

A 1992 study showed that peritoneal macrophages challenged with heat-killed $H$. capsulatum produce prostanoids ( $\mathrm{PGE}_{2}$ and $\mathrm{PGI}_{2}$ ) and LTs $\left(\mathrm{LTB}_{4}\right.$ and $\left.\mathrm{LTC}_{4}\right)$, the former being produced in a COX-dependent fashion [79]. This first observation was the steppingstone for the study of eicosanoids in histoplasmosis. Notably, different forms of LTs and PGs are produced by the host during in vitro and in vivo challenges with H. capsulatum, but, interestingly, they commonly have opposite roles [80,81].

Sub-lethal $H$. capsulatum infections in mice treated with a FLAP inhibitor or in 5LO deficient mice are fatal, suggesting that LTs are important for the host response in histoplasmosis [81,82]. Even though $\mathrm{LTB}_{4}$ and $\mathrm{LTC}_{4}$ are produced in mice infected with $H$. capsulatum [81], data show that administration of microspheres-associated LTB4 to 5-LO deficient mice can restore the production of cytokines and control the fungal burden [83].

Although LTB4 is an important mediator for the host response against $H$. capsulatum, the mechanism behind its effects is controversial. $\mathrm{LTB}_{4}$ is a very potent neutrophil chemoattractant [84], but 5-LO deficient mice and mice treated with FLAP inhibitors have lower levels of LTs and increased neutrophil recruitment when compared to their control counterparts. The increased neutrophil recruitment is followed by higher inflammatory response, an elevation of splenic fungal burdens, and $100 \%$ of mortality 14 days post-infection, even in scenarios of non-lethal H. capsulatum infections [81,82]. This suggests that features other than neutrophil chemotaxis are behind LTs' effects during histoplasmosis. The effector mechanisms employed by macrophages are also responsive to LTs, as 5-LO deficient mice have a remarkable impairment in their ability to phagocytose non-opsonized or even IgG-opsonized H. capsulatum yeast cells, a deficiency that is bypassed by the exogenous 
addition of $\mathrm{LTB}_{4}$ or $\mathrm{LTC}_{4}$ [82]. Although LTs as well as PGs are usually produced at the onset of the inflammatory process, further steps in the host defense are modulated by the presence of these mediators [85]. Immunization of mice with cell-free antigens from $H$. capsulatum fails to confer protection in 5-LO deficient mice, possibly due to an inability to induce the recruitment of CD4+ and CD8+ cells to the lungs, and also a failure to increase the production of IFN- $\gamma$ [86]. The production of LTs has an impact on events of the innate, but also of the adaptive, response during $H$. capsulatum infection, which modifies the outcome of the host-pathogen interaction.

The role of PGs during H. capsulatum infection is not as well studied relative to the leukotrienes. A fundamental piece of data is that the inhibition of COX-2 protects mice against lethal infection with $H$. capsulatum, a phenotype marked by lower fungal burden and a milder inflammatory process [80]. Curiously, when inhibiting the synthesis of prostanoids, an increase in the synthesis of $\mathrm{LTB}_{4}$ is observed, which is also beneficial to the host. The higher survival rates are associated with a decrease in neutrophil recruitment, consistent with the effects of LTs [80]. PGE $_{2}$ has been associated with the deleterious effects on H. capsulatum infection [16], which correlates with the expression and activity of galectin1 (Gal-1) [87]. Gal-1 represses the expression of $\mathrm{PGE}_{2}$ synthase, thus reducing the levels of $\mathrm{PGE}_{2}$ in $H$. capsulatum-infected mice. In contrast, $H$. capsulatum infection in Gal-1 $\mathrm{KO}$ mice leads to an increase in $\mathrm{PGE}_{2}$ production followed by increased fungal burden and higher mortality rates when compared to WT mice [87]. Even though $\mathrm{PGE}_{2}$ has such deleterious effects to the infected host, $\mathrm{PGD}_{2}$ has opposite effects to $\mathrm{PGE}_{2}$. The pharmacological inhibition of the endogenous production of $\mathrm{PGD}_{2}$ in $\mathrm{H}$. capsulatum-infected macrophages leads to a severe inhibition of the leukocyte's fungicidal activity, an effect that is reversed by the exogenous addition of $\mathrm{PGD}_{2}$. $\mathrm{PGD}_{2}$ also upregulates the expression of $\mathrm{LTB}_{4}$ receptor (BLT1R), potentiating the effects of $\mathrm{LTB}_{4}$ [87]. The role and mechanism of eicosanoids in the host response against $H$. capsulatum is still understudied, but data suggest that $\mathrm{LTB}_{4}$ and $\mathrm{PGE}_{2}$ have opposite effects in histoplasmosis by modulating the recruitment of neutrophils and the effector mechanisms of macrophages. In agreement, $\mathrm{PGE}_{2}$ also inhibits the production of hydrogen peroxide and TNF- $\alpha$ by monocytes, limiting the killing of Paracoccidioides brasiliensis [88]. Further studies are necessary to dissect whether other eicosanoids have a role in the infection by $H$. capsulatum, including ones of fungal origin and also the mechanisms involved in immune regulation.

\section{Concluding Remarks}

Human pathogenic fungal species such as Candida spp., C. neoformans and H. capsulatum produce eicosanoids. C. albicans utilizes exogenous AA in order to produce 3,18-di HET, $\mathrm{LTB}_{4}$, Cys-LTs, RvE1 and prostaglandins such as $\mathrm{PGE}_{2}, \mathrm{PGD}_{2}, \mathrm{PGF}_{\alpha}$. Non-albicans Candida species such as C. dubliniensis, C. tropicalis, C. glabrata, and C. parapsilosis also synthesize $\mathrm{PGE}_{2}$ from AA. Additionally, C. parapsilosis produces other prostaglandins such as $\mathrm{PGD}_{2}$ and $15-\mathrm{keto}_{\mathrm{PGE}}$. The exact molecular mechanisms behind the Candida-derived eicosanoid production are only uncovered in the case of PGs in C. albicans and C. parapsilosis. $\mathrm{PGE}_{2}$ synthesis in C. albicans is regulated by OLE2, while C. parapsilosis evolved OLE2-independent PGs production pathways. This difference may explain the contrast in in vivo results: $C$. albicans-derived $\mathrm{PGE}_{2}$ is not required for virulence while PGs produced by $C$. parapsilosis influence the yeast's capacity for host damage. Overall, the presence of fungal $\mathrm{PGE}_{2}$ has proven to be beneficial for $C$. albicans through increasing the ability of the pathogen to colonize the gut. Furthermore, fungal $\mathrm{PGE}_{2}$ protects $C$. albicans and C. parapsilosis cells from the phagocytic and killing activity of macrophages. C. albicansderived RvE1 protects the fungus at low concentrations, whereas high concentrations expose the fungus to the host. C. neoformans produces $15-K_{\text {Keto- }} \mathrm{PGE}_{2}$ to enhance its growth and ability to survive macrophage infection. In histoplasmosis, the inhibition of the PGs production is beneficial to the host as it favors $\mathrm{LTB}_{4}$ production, which induces a decrease in the fungal burden, mortality rates and neutrophil recruitment. $\mathrm{PGE}_{2}$ has deleterious effects on histoplasmosis, as opposed to the positive effects of $\mathrm{PGD}_{2}$, which upregulates the 
expression of BLT1R in H. capsulatum infected macrophages and potentiates the effects of $\mathrm{LTB}_{4}$. LTs are important for the host response, as, for example, $\mathrm{LTB}_{4}$ mediates the immune response helping to control the fungal burden. However, the mechanism behind its effect is controversial as $\mathrm{LTB}_{4}$ is a neutrophil chemoattractant and mice with lower levels of LTs have increased inflammatory responses, fungal burdens and mortality rates. However, further investigations are needed to understand the precise role of eicosanoids, mainly $\mathrm{PGE}_{2}$, during host-pathogen interactions.

\title{
5. Future Trends
}

The production of eicosanoids seems to be a conserved feature among several eukaryotic organisms, including filamentous and yeast fungi, protozoa and higher eukaryotes such as mammals. Independently on the organism, their biosynthetic pathways may vary considerably, as well as the full eicosanoid portfolio produced. Since pathogenic fungi are able to secrete these molecules, the exact mechanism in how they alter the microbial physiology has not been fully explored, although current research and published data have demonstrated their effects on the modulation of interactions with the host and immune responses.

Then, as it is completely plausible that fungal eicosanoids might function as virulence factors, further investigations might enable us to understand their precise role during host-pathogen interactions, as well as exploring the unique steps of the fungal eicosanoids biosynthesis, as a new potential target to combat C. albicans, C. parapsilosis, C. neoformans and $H$. capsulatum and possibly other fungal infections.

Author Contributions: S.R.M.; D.Z.-M.; T.T.; A.G.; J.D.N. and A.J.G. All authors have read and agreed to the published version of the manuscript.

Funding: A.J.G. was supported by grants from the Brazilian agencies Conselho Nacional de Desenvolvimento Científico e Tecnológico (CNPq, grants 311470/2018-1) and Fundação Carlos Chagas de Amparo à Pesquisa no Estado do Rio de Janeiro (E-26/202.696/2018). S.R.M. was supported by CAPES (Coordenação de Aperfeiçoamento de Pessoal de Nível Superior).

Institutional Review Board Statement: Not applicable.

Conflicts of Interest: The authors declare no conflict of interest.

\author{
Abbreviations \\ 15-keto-PGE2 Dehydrogenated form of Prostaglandin $E_{2}$ \\ 3-HETE 3-hydroxy-5,8,11,14- eicosatetraenoic acid \\ 3,18-di-HETE 3,18-dihydroxy-5,8,11,14- eicosatetraenoic acid \\ 5- HpETE 5-hydroperoxyeicosatetraenoic acid \\ 5-LO Enzyme 5-lipoxygenase \\ AA Arachidonic acid \\ AA (20:4, n-6) Arachidonic acid (20-carbon, 4 insaturations, omega 6 family) \\ ABC ATP-binding cassette transporter \\ APCs Antigen presenting cells \\ BLT1 Leukotriene B4 high-affinity receptor \\ BLT2 Leukotriene B4 Low-affinity receptor \\ CaFET3 Candida albicans multicopper ferroxidase \\ cAMP Cyclic adenosine monophosphate \\ CaOLE2 C. albicans fatty acid stearyl-coenzyme A desaturase \\ CNLAC1 Cryptococcus neoformans laccase gene \\ CNS Central nervous system \\ COX Cyclooxygenase \\ CRTH2 Chemoattractant receptor-homologous molecule expressed on Th2 cells; \\ also known as DP2, PG DP2 receptor
}




\begin{tabular}{|c|c|}
\hline CysLT & Cysteinyl leukotriene \\
\hline CysLTR1 & Type 1 cysteinyl leukotriene receptor \\
\hline CYTP450 & Cytochrome P450 oxidase \\
\hline DCs & Dendritic cells \\
\hline DHA & Docosahexaenoic acid \\
\hline DP1 & Prostaglandin $\mathrm{D}_{2}$ receptor 1 \\
\hline $\mathrm{EP}(1-4)$ & Rhodopsin-type receptors \\
\hline EPA & Eicosapentaenoic acid \\
\hline ERKs & Extracellular signal-regulate kinases \\
\hline FAs & Fatty acids \\
\hline FLA & 5-lipoxygenase activating protein \\
\hline $\mathrm{FP}$ & Prostaglandin F receptor \\
\hline Gal-1 & Galectin-1 \\
\hline GPCRs & G-protein coupled receptors \\
\hline IL & Interleukin \\
\hline IP & Prostacyclin receptor \\
\hline LOX & Lipoxygenase \\
\hline LPL & Lysophospholipase \\
\hline LPTA & Lysophospholipase transacylase \\
\hline LT & Leukotriene \\
\hline LTA4 & Leukotriene $\mathrm{A}_{4}$ \\
\hline LTA4H & $\mathrm{LTA}_{4}$ hydrolase \\
\hline LTB4 & Leukotriene $\mathrm{B}_{4}$ \\
\hline LTD4 & Leukotriene $\mathrm{D}_{4}$ \\
\hline LTE4 & Leukotriene $\mathrm{E}_{4}$ \\
\hline LTF4 & Leukotriene $\mathrm{F}_{4}$ \\
\hline LTs & Leukotrienes \\
\hline$n-3$ & Omega-3 \\
\hline$n-6$ & Omega-6 \\
\hline PBMC- DM & Peripheral blood monocyte-derived macrophages \\
\hline PGs & Prostaglandins \\
\hline $\mathrm{PGD}_{2}$ & Prostaglandin $\mathrm{D}_{2}$ \\
\hline $\mathrm{PGE}_{2}$ & Prostaglandin $\mathrm{E}_{2}$ \\
\hline $\mathrm{PGE}_{\mathrm{x}}$ & Uncharacterized prostaglandin \\
\hline $\mathrm{PGF}_{2}$ & Prostaglandin $\mathrm{F}_{2}$ \\
\hline $\mathrm{PGG}_{2}$ & Prostaglandin $\mathrm{G}_{2}$ \\
\hline $\mathrm{PGH}_{2}$ & Prostaglandin $\mathrm{H}_{2}$ \\
\hline $\mathrm{PGI}_{2}$ & Prostacyclin \\
\hline PI3K & Phosphoinositide 3-kinase \\
\hline PKA & Protein kinase A \\
\hline PLA & Phospholipase A \\
\hline PLB & Phospholipase B \\
\hline PMN & Polymorphonuclear neutrophil \\
\hline PUFA & Polyunsaturated fatty acids \\
\hline Rvs & Resolvins \\
\hline RvD & D-series Resolvins (RvD1-6) \\
\hline RvE1 & E-series Resolvins (RvE1-3) \\
\hline RvT & 13-series resolvins \\
\hline SPM & Specialized pro-resolving mediator \\
\hline Th & T-helper \\
\hline TNF- $\alpha$ & Tumor necrosis factor alpha \\
\hline $\mathrm{TP}$ & Thromboxane receptor \\
\hline TX & Thromboxane \\
\hline TXA2 & Thromboxane A2 \\
\hline TXS & Thromboxane synthase \\
\hline$\Delta$ lac1 & Laccase gene Cryptococcus neoformans mutant \\
\hline$\Delta \mathrm{plb} 1$ & Phospholipase B1 Cryptococcus neoformans mutant \\
\hline
\end{tabular}




\section{References}

1. Kanamori, H.; Rutala, W.A.; Sickbert-Bennett, E.E.; Weber, D.J. Review of Fungal Outbreaks and Infection Prevention in Healthcare Settings during Construction and Renovation. Clin. Infect. Dis. Off. Publ. Infect. Dis. Soc. Am. 2015, 61, 433-444. [CrossRef] [PubMed]

2. Spitzer, M.; Robbins, N.; Wright, G.D. Combinatorial Strategies for Combating Invasive Fungal Infections. Virulence 2017, 8 , 169-185. [CrossRef] [PubMed]

3. Janbon, G.; Quintin, J.; Lanternier, F.; d’Enfert, C. Studying Fungal Pathogens of Humans and Fungal Infections: Fungal Diversity and Diversity of Approaches. Genes Immun. 2019, 20, 403-414. [CrossRef]

4. $\quad$ Ells, R.; Kock, J.L.; Albertyn, J.; Pohl, C.H. Arachidonic Acid Metabolites in Pathogenic Yeasts. Lipids Health Dis. 2012, 11, 100. [CrossRef] [PubMed]

5. Harris, S.G.; Padilla, J.; Koumas, L.; Ray, D.; Phipps, R.P. Prostaglandins as Modulators of Immunity. Trends Immunol. 2002, 23, 144-150. [CrossRef]

6. Ghannoum, M.A. Potential Role of Phospholipases in Virulence and Fungal Pathogenesis. Clin. Microbiol. Rev. 2000, 13, 122-143, table of contents. [CrossRef]

7. Tilley, S.L.; Coffman, T.M.; Koller, B.H. Mixed Messages: Modulation of Inflammation and Immune Responses by Prostaglandins and Thromboxanes. J. Clin. Investig. 2001, 108, 15-23. [CrossRef] [PubMed]

8. Christie, W.W.; Harwood, J.L. Oxidation of Polyunsaturated Fatty Acids to Produce Lipid Mediators. Essays Biochem. 2020, 64, 401-421. [CrossRef]

9. Ghannoum, M.A. Extracellular Phospholipases as Universal Virulence Factor in Pathogenic Fungi. Nihon Ishinkin Gakkai Zasshi Jpn. J. Med. Mycol. 1998, 39, 55-59. [CrossRef]

10. Lehninger, A.L.; Nelson, D.L.; Cox, M.M. Lehninger Principles of Biochemistry, 4th ed.; W.H. Freeman: New York, NY, USA, 2005; ISBN 978-0-7167-4339-2.

11. Serhan, C.N. Novel Eicosanoid and Docosanoid Mediators: Resolvins, Docosatrienes, and Neuroprotectins. Curr. Opin. Clin. Nutr. Metab. Care 2005, 8, 115-121. [CrossRef]

12. Serhan, C.N.; Gotlinger, K.; Hong, S.; Arita, M. Resolvins, Docosatrienes, and Neuroprotectins, Novel Omega-3-Derived Mediators, and Their Aspirin-Triggered Endogenous Epimers: An Overview of Their Protective Roles in Catabasis. Prostagland. Other Lipid Mediat. 2004, 73, 155-172. [CrossRef] [PubMed]

13. Noverr, M.C.; Toews, G.B.; Huffnagle, G.B. Production of Prostaglandins and Leukotrienes by Pathogenic Fungi. Infect. Immun. 2002, 70, 400-402. [CrossRef] [PubMed]

14. Martínez-Colón, G.J.; Moore, B.B. Prostaglandin E2 as a Regulator of Immunity to Pathogens. Pharmacol. Ther. 2018, 185, 135-146. [CrossRef]

15. Coleman, R.A.; Smith, W.L.; Narumiya, S. International Union of Pharmacology Classification of Prostanoid Receptors: Properties, Distribution, and Structure of the Receptors and Their Subtypes. Pharmacol. Rev. 1994, 46, 205-229.

16. Pereira, P.A.T.; Assis, P.A.; Prado, M.K.B.; Ramos, S.G.; Aronoff, D.M.; de Paula-Silva, F.W.G.; Sorgi, C.A.; Faccioli, L.H. Prostaglandins D2 and E2 Have Opposite Effects on Alveolar Macrophages Infected with Histoplasma Capsulatum. J. Lipid Res. 2018, 59, 195-206. [CrossRef]

17. Hardwick, J.P.; Eckman, K.; Lee, Y.K.; Abdelmegeed, M.A.; Esterle, A.; Chilian, W.M.; Chiang, J.Y.; Song, B.-J. Eicosanoids in Metabolic Syndrome. Adv. Pharmacol. 2013, 66, 157-266. [CrossRef]

18. Jones, R.L. Prostanoid Receptors. In $x$ Pharm: The Comprehensive Pharmacology Reference; Elsevier: Amsterdam, The Netherlands, 2007; pp. 1-3. ISBN 978-0-08-055232-3.

19. Sun, L.; Ye, R.D. Role of G Protein-Coupled Receptors in Inflammation. Acta Pharmacol. Sin. 2012, 33, 342-350. [CrossRef]

20. Sugimoto, Y.; Narumiya, S. Prostaglandin E Receptors. J. Biol. Chem. 2007, 282, 11613-11617. [CrossRef]

21. Narumiya, S.; Sugimoto, Y.; Ushikubi, F. Prostanoid Receptors: Structures, Properties, and Functions. Physiol. Rev. 1999, 79, 1193-1226. [CrossRef] [PubMed]

22. Woodward, D.F.; Jones, R.L.; Narumiya, S. International Union of Basic and Clinical Pharmacology. LXXXIII: Classification of Prostanoid Receptors, Updating 15 Years of Progress. Pharmacol. Rev. 2011, 63, 471-538. [CrossRef] [PubMed]

23. Tsuge, K.; Inazumi, T.; Shimamoto, A.; Sugimoto, Y. Molecular Mechanisms Underlying Prostaglandin E2-Exacerbated Inflammation and Immune Diseases. Int. Immunol. 2019, 31, 597-606. [CrossRef] [PubMed]

24. Cheng, X.; Ji, Z.; Tsalkova, T.; Mei, F. Epac and PKA: A Tale of Two Intracellular CAMP Receptors. Acta Biochim. Biophys. Sin. 2008, 40, 651-662. [CrossRef] [PubMed]

25. Regan, J.W. EP2 and EP4 Prostanoid Receptor Signaling. Life Sci. 2003, 74, 143-153. [CrossRef]

26. Breyer, R.M.; Bagdassarian, C.K.; Myers, S.A.; Breyer, M.D. Prostanoid Receptors: Subtypes and Signaling. Annu. Rev. Pharmacol. Toxicol. 2001, 41, 661-690. [CrossRef]

27. Kobayashi, K.; Horikami, D.; Omori, K.; Nakamura, T.; Yamazaki, A.; Maeda, S.; Murata, T. Thromboxane A2 Exacerbates Acute Lung Injury via Promoting Edema Formation. Sci. Rep. 2016, 6, 32109. [CrossRef]

28. Altieri, D.C.; Mannucci, P.M. Thromboxane Generation by Human Monocytes Enhances Platelet Function. J. Exp. Med. 1986, 164, 1815-1820. [CrossRef] 
29. Ashton, A.W.; Mukherjee, S.; Nagajyothi, F.N.U.; Huang, H.; Braunstein, V.L.; Desruisseaux, M.S.; Factor, S.M.; Lopez, L.; Berman, J.W.; Wittner, M.; et al. Thromboxane A2 Is a Key Regulator of Pathogenesis during Trypanosoma Cruzi Infection. J. Exp. Med. 2007, 204, 929-940. [CrossRef]

30. Yang, C.-W.; Unanue, E.R. Neutrophils Control the Magnitude and Spread of the Immune Response in a Thromboxane A2Mediated Process. J. Exp. Med. 2013, 210, 375-387. [CrossRef]

31. Peters-Golden, M.; Canetti, C.; Mancuso, P.; Coffey, M.J. Leukotrienes: Underappreciated Mediators of Innate Immune Responses. J. Immunol. 2005, 174, 589-594. [CrossRef]

32. Morato-Marques, M.; Campos, M.R.; Kane, S.; Rangel, A.P.; Lewis, C.; Ballinger, M.N.; Kim, S.-H.; Peters-Golden, M.; Jancar, S.; Serezani, C.H. Leukotrienes Target F-Actin/Cofilin-1 to Enhance Alveolar Macrophage Anti-Fungal Activity. J. Biol. Chem. 2011, 286, 28902-28913. [CrossRef] [PubMed]

33. Tager, A.M.; Luster, A.D. BLT1 and BLT2: The Leukotriene B(4) Receptors. Prostagland. Leukot. Essent. Fatty Acids 2003, 69, 123-134. [CrossRef]

34. Kanaoka, Y.; Boyce, J.A. Cysteinyl Leukotrienes and Their Receptors; Emerging Concepts. Allergy Asthma Immunol. Res. 2014, 6, 288-295. [CrossRef]

35. Melo, C.F.O.R.; Bachur, L.F.; Delafiori, J.; Dabaja, M.Z.; de Oliveira, D.N.; Guerreiro, T.M.; Tararam, C.A.; Busso-Lopes, A.F.; Moretti, M.L.; Catharino, R.R. Does Leukotriene F4 Play a Major Role in the Infection Mechanism of Candida Sp.? Microb. Pathog. 2020, 149, 104394. [CrossRef] [PubMed]

36. Oliveira, S.H.P.; Canetti, C.; Ribeiro, R.A.; Cunha, F.Q. Neutrophil Migration Induced by IL-1beta Depends upon LTB4 Released by Macrophages and upon TNF-Alpha and IL-1beta Released by Mast Cells. Inflammation 2008, 31, 36-46. [CrossRef] [PubMed]

37. Olynych, T.J.; Jakeman, D.L.; Marshall, J.S. Fungal Zymosan Induces Leukotriene Production by Human Mast Cells through a Dectin-1-Dependent Mechanism. J. Allergy Clin. Immunol. 2006, 118, 837-843. [CrossRef]

38. König, S.; Pace, S.; Pein, H.; Heinekamp, T.; Kramer, J.; Romp, E.; Straßburger, M.; Troisi, F.; Proschak, A.; Dworschak, J.; et al. Gliotoxin from Aspergillus Fumigatus Abrogates Leukotriene B4 Formation through Inhibition of Leukotriene A4 Hydrolase. Cell Chem. Biol. 2019, 26, 524-534.e5. [CrossRef]

39. Lee, E.K.S.; Gillrie, M.R.; Li, L.; Arnason, J.W.; Kim, J.H.; Babes, L.; Lou, Y.; Sanati-Nezhad, A.; Kyei, S.K.; Kelly, M.M.; et al. Leukotriene B4-Mediated Neutrophil Recruitment Causes Pulmonary Capillaritis during Lethal Fungal Sepsis. Cell Host Microbe 2018, 23, 121-133.e4. [CrossRef]

40. Caffrey-Carr, A.K.; Hilmer, K.M.; Kowalski, C.H.; Shepardson, K.M.; Temple, R.M.; Cramer, R.A.; Obar, J.J. Host-Derived Leukotriene B4 Is Critical for Resistance against Invasive Pulmonary Aspergillosis. Front. Immunol. 2017, 8, 1984. [CrossRef]

41. Spite, M. Deciphering the Role of N-3 Polyunsaturated Fatty Acid-Derived Lipid Mediators in Health and Disease. Proc. Nutr. Soc. 2013, 72, 441-450. [CrossRef] [PubMed]

42. Haas-Stapleton, E.J.; Lu, Y.; Hong, S.; Arita, M.; Favoreto, S.; Nigam, S.; Serhan, C.N.; Agabian, N. Candida Albicans Modulates Host Defense by Biosynthesizing the Pro-Resolving Mediator Resolvin E1. PLoS ONE 2007, 2, e0001316. [CrossRef] [PubMed]

43. Schwab, J.M.; Chiang, N.; Arita, M.; Serhan, C.N. Resolvin E1 and Protectin D1 Activate Inflammation-Resolution Programmes. Nature 2007, 447, 869-874. [CrossRef]

44. Serhan, C.N. Resolution Phase of Inflammation: Novel Endogenous Anti-Inflammatory and Proresolving Lipid Mediators and Pathways. Annu. Rev. Immunol. 2007, 25, 101-137. [CrossRef]

45. Sommer, C.; Birklein, F. Resolvins and Inflammatory Pain. F1000 Med. Rep. 2011, 3, 19. [CrossRef] [PubMed]

46. Buczynski, M.W.; Dumlao, D.S.; Dennis, E.A. Thematic Review Series: Proteomics. An Integrated Omics Analysis of Eicosanoid Biology. J. Lipid Res. 2009, 50, 1015-1038. [CrossRef] [PubMed]

47. van Dyk, M.S.; Kock, J.L.; Coetzee, D.J.; Augustyn, O.P.; Nigam, S. Isolation of a Novel Arachidonic Acid Metabolite 3-Hydroxy5,8,11,14-Eicosatetraenoic Acid (3-HETE) from the Yeast Dipodascopsis Uninucleata UOFs-Y128. FEBS Lett. 1991, 283, 195-198. [CrossRef]

48. Strauss, T.; Botha, A.; Kock, J.L.; Paul, I.; Smith, D.P.; Linke, D.; Schewe, T.; Nigam, S. Mapping the Distribution of 3-Hydroxylipins in the Mucorales Using Immunofluorescence Microscopy. Antonie Van Leeuwenhoek 2000, 78, 39-42. [CrossRef]

49. Botha, A.; Kock, J.L.F.; Coetzee, D.J.; Van Dyk, M.S.; Van Der Berg, L.; Botes, P.J. Yeast Eicosanoids I. The Distribution and Taxonomic Value of Cellular Fatty Acids and Arachidonic Acid Metabolites in the Dipodascaceae and Related Taxa. Syst. Appl. Microbiol. 1992, 15, 148-154. [CrossRef]

50. Noverr, M.C.; Phare, S.M.; Toews, G.B.; Coffey, M.J.; Huffnagle, G.B. Pathogenic Yeasts Cryptococcus Neoformans and Candida Albicans Produce Immunomodulatory Prostaglandins. Infect. Immun. 2001, 69, 2957-2963. [CrossRef]

51. Erb-Downward, J.R.; Noggle, R.M.; Williamson, P.R.; Huffnagle, G.B. The Role of Laccase in Prostaglandin Production by Cryptococcus Neoformans. Mol. Microbiol. 2008, 68, 1428-1437. [CrossRef]

52. Erb-Downward, J.R.; Noverr, M.C. Characterization of Prostaglandin E2 Production by Candida Albicans. Infect. Immun. 2007, 75, 3498-3505. [CrossRef]

53. Deva, R.; Ciccoli, R.; Kock, L.; Nigam, S. Involvement of Aspirin-Sensitive Oxylipins in Vulvovaginal Candidiasis. FEMS Microbiol. Lett. 2001, 198, 37-43. [CrossRef] [PubMed]

54. Noverr, M.C.; Erb-Downward, J.R.; Huffnagle, G.B. Production of Eicosanoids and Other Oxylipins by Pathogenic Eukaryotic Microbes. Clin. Microbiol. Rev. 2003, 16, 517-533. [CrossRef] 
55. Alem, M.A.; Douglas, L.J. Prostaglandin Production during Growth of Candida Albicans Biofilms. J. Med. Microbiol. 2005, 54, 1001-1005. [CrossRef]

56. Grózer, Z.; Tóth, A.; Tóth, R.; Kecskeméti, A.; Vágvölgyi, C.; Nosanchuk, J.D.; Szekeres, A.; Gácser, A. Candida Parapsilosis Produces Prostaglandins from Exogenous Arachidonic Acid and OLE2 Is Not Required for Their Synthesis. Virulence 2015, 6, 85-92. [CrossRef] [PubMed]

57. Chakraborty, T.; Thuer, E.; Heijink, M.; Tóth, R.; Bodai, L.; Vágvölgyi, C.; Giera, M.; Gabaldón, T.; Gácser, A. Eicosanoid Biosynthesis Influences the Virulence of Candida Parapsilosis. Virulence 2018, 9, 1019-1035. [CrossRef]

58. Mishra, N.N.; Ali, S.; Shukla, P.K. Arachidonic Acid Affects Biofilm Formation and PGE2 Level in Candida Albicans and Non-Albicans Species in Presence of Subinhibitory Concentration of Fluconazole and Terbinafine. Braz. J. Infect. Dis. Off. Publ. Braz. Soc. Infect. Dis. 2014, 18, 287-293. [CrossRef]

59. Arita, M.; Bianchini, F.; Aliberti, J.; Sher, A.; Chiang, N.; Hong, S.; Yang, R.; Petasis, N.A.; Serhan, C.N. Stereochemical Assignment, Antiinflammatory Properties, and Receptor for the Omega-3 Lipid Mediator Resolvin E1. J. Exp. Med. 2005, 201, 713-722. [CrossRef] [PubMed]

60. Evans, R.J.; Pline, K.; Loynes, C.A.; Needs, S.; Aldrovandi, M.; Tiefenbach, J.; Bielska, E.; Rubino, R.E.; Nicol, C.J.; May, R.C.; et al. 15-Keto-Prostaglandin E2 Activates Host Peroxisome Proliferator-Activated Receptor Gamma (PPAR- $\gamma$ ) to Promote Cryptococcus Neoformans Growth during Infection. PLoS Pathog. 2019, 15, e1007597. [CrossRef] [PubMed]

61. Ganendren, R.; Widmer, F.; Singhal, V.; Wilson, C.; Sorrell, T.; Wright, L. In Vitro Antifungal Activities of Inhibitors of Phospholipases from the Fungal Pathogen Cryptococcus Neoformans. Antimicrob. Agents Chemother. 2004, 48, 1561-1569. [CrossRef] [PubMed]

62. Panepinto, J.C.; Williamson, P.R. Intersection of Fungal Fitness and Virulence in Cryptococcus Neoformans. FEMS Yeast Res. 2006, 6, 489-498. [CrossRef] [PubMed]

63. Zhu, X.; Williamson, P.R. Role of Laccase in the Biology and Virulence of Cryptococcus Neoformans. FEMS Yeast Res. 2004, 5, 1-10. [CrossRef] [PubMed]

64. Valdez, P.A.; Vithayathil, P.J.; Janelsins, B.M.; Shaffer, A.L.; Williamson, P.R.; Datta, S.K. Prostaglandin E2 Suppresses Antifungal Immunity by Inhibiting Interferon Regulatory Factor 4 Function and Interleukin-17 Expression in T Cells. Immunity 2012, 36, 668-679. [CrossRef] [PubMed]

65. Tan, T.G.; Lim, Y.S.; Tan, A.; Leong, R.; Pavelka, N. Fungal Symbionts Produce Prostaglandin E2 to Promote Their Intestinal Colonization. Front. Cell. Infect. Microbiol. 2019, 9, 359. [CrossRef] [PubMed]

66. Filler, S.G.; Ibe, B.O.; Luckett, P.M.; Raj, J.U.; Edwards, J.E. Candida Albicans Stimulates Endothelial Cell Eicosanoid Production. J. Infect. Dis. 1991, 164, 928-935. [CrossRef]

67. Ma, H.; Wan, S.; Xia, C.-Q. Immunosuppressive CD11b+Ly6Chi Monocytes in Pristane-Induced Lupus Mouse Model. J. Leukoc. Biol. 2016, 99, 1121-1129. [CrossRef]

68. Yao, C.; Sakata, D.; Esaki, Y.; Li, Y.; Matsuoka, T.; Kuroiwa, K.; Sugimoto, Y.; Narumiya, S. Prostaglandin E2-EP4 Signaling Promotes Immune Inflammation through Th1 Cell Differentiation and Th17 Cell Expansion. Nat. Med. 2009, 15, 633-640. [CrossRef]

69. Chizzolini, C.; Chicheportiche, R.; Alvarez, M.; de Rham, C.; Roux-Lombard, P.; Ferrari-Lacraz, S.; Dayer, J.-M. Prostaglandin E2 Synergistically with Interleukin-23 Favors Human Th17 Expansion. Blood 2008, 112, 3696-3703. [CrossRef]

70. Castro, M.; Ralston, N.V.; Morgenthaler, T.I.; Rohrbach, M.S.; Limper, A.H. Candida Albicans Stimulates Arachidonic Acid Liberation from Alveolar Macrophages through Alpha-Mannan and Beta-Glucan Cell Wall Components. Infect. Immun. 1994, 62, 3138-3145. [CrossRef] [PubMed]

71. Smeekens, S.P.; van de Veerdonk, F.L.; van der Meer, J.W.M.; Kullberg, B.J.; Joosten, L.A.B.; Netea, M.G. The Candida Th17 Response Is Dependent on Mannan- and -Glucan-Induced Prostaglandin E2. Int. Immunol. 2010, 22, 889-895. [CrossRef]

72. Kalo-Klein, A.; Witkin, S.S. Prostaglandin E2 Enhances and Gamma Interferon Inhibits Germ Tube Formation in Candida Albicans. Infect. Immun. 1990, 58, 260-262. [CrossRef]

73. Kim, Y.-G.; Udayanga, K.G.S.; Totsuka, N.; Weinberg, J.B.; Núñez, G.; Shibuya, A. Gut Dysbiosis Promotes M2 Macrophage Polarization and Allergic Airway Inflammation via Fungi-Induced PGE 2 . Cell Host Microbe 2014, 15, 95-102. [CrossRef] [PubMed]

74. Bernström, K.; Hammarström, S. A Novel Leukotriene Formed by Transpeptidation of Leukotriene E. Biochem. Biophys. Res. Commun. 1982, 109, 800-804. [CrossRef]

75. Singh, R.K.; Gupta, S.; Dastidar, S.; Ray, A. Cysteinyl Leukotrienes and Their Receptors: Molecular and Functional Characteristics. Pharmacology 2010, 85, 336-349. [CrossRef] [PubMed]

76. Sun, D.; Shi, M. Neutrophil Swarming toward Cryptococcus Neoformans Is Mediated by Complement and Leukotriene B4. Biochem. Biophys. Res. Commun. 2016, 477, 945-951. [CrossRef]

77. Zhu, L.; Maruvada, R.; Sapirstein, A.; Peters-Golden, M.; Kim, K.S. Cysteinyl Leukotrienes as Novel Host Factors Facilitating Cryptococcus Neoformans Penetration into the Brain. Cell. Microbiol. 2017, 19, e12661. [CrossRef] [PubMed]

78. Shen, L.; Liu, Y. Prostaglandin E2 Blockade Enhances the Pulmonary Anti-Cryptococcus Neoformans Immune Reaction via the Induction of TLR-4. Int. Immunopharmacol. 2015, 28, 376-381. [CrossRef]

79. Wolf, J.E.; Massof, S.E.; Peters, S.P. Alterations in Murine Macrophage Arachidonic Acid Metabolism Following Ingestion of Nonviable Histoplasma Capsulatum. Infect. Immun. 1992, 60, 2559-2564. [CrossRef] [PubMed] 
80. Pereira, P.A.T.; Trindade, B.C.; Secatto, A.; Nicolete, R.; Peres-Buzalaf, C.; Ramos, S.G.; Sadikot, R.; Bitencourt, C.D.S.; Faccioli, L.H. Celecoxib Improves Host Defense through Prostaglandin Inhibition during Histoplasma Capsulatum Infection. Mediat. Inflamm. 2013, 2013, 950981. [CrossRef]

81. Medeiros, A.I.; Sá-Nunes, A.; Soares, E.G.; Peres, C.M.; Silva, C.L.; Faccioli, L.H. Blockade of Endogenous Leukotrienes Exacerbates Pulmonary Histoplasmosis. Infect. Immun. 2004, 72, 1637-1644. [CrossRef]

82. Secatto, A.; Rodrigues, L.C.; Serezani, C.H.; Ramos, S.G.; Dias-Baruffi, M.; Faccioli, L.H.; Medeiros, A.I. 5-Lipoxygenase Deficiency Impairs Innate and Adaptive Immune Responses during Fungal Infection. PLoS ONE 2012, 7, e31701. [CrossRef]

83. Nicolete, R.; Secatto, A.; Pereira, P.A.T.; Soares, E.G.; Faccioli, L.H. Leukotriene B4-Loaded Microspheres as a New Approach to Enhance Antimicrobial Responses in Histoplasma Capsulatum-Infected Mice. Int. J. Antimicrob. Agents 2009, 34, 365-369. [CrossRef] [PubMed]

84. Metzemaekers, M.; Gouwy, M.; Proost, P. Neutrophil Chemoattractant Receptors in Health and Disease: Double-Edged Swords. Cell. Mol. Immunol. 2020, 17, 433-450. [CrossRef] [PubMed]

85. Samuchiwal, S.K.; Boyce, J.A. Role of Lipid Mediators and Control of Lymphocyte Responses in Type 2 Immunopathology. J. Allergy Clin. Immunol. 2018, 141, 1182-1190. [CrossRef] [PubMed]

86. Medeiros, A.I.; Sá-Nunes, A.; Turato, W.M.; Secatto, A.; Frantz, F.G.; Sorgi, C.A.; Serezani, C.H.; Deepe, G.S.; Faccioli, L.H. Leukotrienes Are Potent Adjuvant during Fungal Infection: Effects on Memory T Cells. J. Immunol. 2008, 181, $8544-8551$. [CrossRef] [PubMed]

87. Rodrigues, L.C.; Secatto, A.; Sorgi, C.A.; Dejani, N.N.; Medeiros, A.I.; Prado, M.K.B.; Ramos, S.G.; Cummings, R.D.; Stowell, S.R.; Faccioli, L.H.; et al. Protective Effect of Galectin-1 during Histoplasma Capsulatum Infection Is Associated with Prostaglandin E2 and Nitric Oxide Modulation. Mediat. Inflamm. 2016, 2016, 5813794. [CrossRef]

88. Bordon, A.P.; Dias-Melicio, L.A.; Acorci, M.J.; Calvi, S.A.; Serrão Peraçoli, M.T.; Victoriano de Campos Soares, A.M. Prostaglandin E2 Inhibits Paracoccidioides Brasiliensis Killing by Human Monocytes. Microbes Infect. 2007, 9, 744-747. [CrossRef] 